\title{
Primary headaches: dysfunctional pains
}

Cefaleias primárias: dores disfuncionais

Jose Geraldo Speciali' ${ }^{1}$, Norma Regina Pereira Fleming ${ }^{2}$, Ida Fortini ${ }^{3}$

DOI 10.5935/1806-0013.20160053

\section{ABSTRACT}

BACKGROUND AND OBJECTIVES: Headache is a very prevalent symptom, being considered the second more frequent type of pain by international epidemiological studies. It is also an expensive symptom for patients, relatives, society and general health systems, impairing quality of life of those suffering from this problem. Primary headaches, among them migraine and tension headache are classified as dysfunctional headaches. It is important to understand why these two disorders cannot be seen as somatic, neuropathic or visceral pain. This article shall use the terms migraine and megrim as synonyms. This study aimed at defining dysfunctional pain and at justifying why primary headaches are considered dysfunctional pain.

CONTENTS: a) Migraine pathophysiology, most prevalent primary headache in medical offices, it is explained as a disease made up of crises which may have up to five phases and not simply as a headache. Migraine crisis phases are: premonitory symptoms, aura, headache, autonomic/hypothalamic symptoms and posdrome. b) Classify migraine as dysfunctional pain because it does not meet criteria to be classified as neuropathic or somatic pain. c) Discuss which type of pain secondary headaches are.

CONCLUSION: It is possible to accept the idea that primary headaches are demodulatory pains, but that secondary headaches are nociceptive or visceral. Keywords: Dysfunctional pain, Headache, Megrim or migraine, Secondary headaches.

\section{RESUMO}

JUSTIFICATIVA E OBJETIVOS: Cefaleia é um sintoma muito prevalente, sendo considerado o segunto tipo mais frequente de dor em estudos epidemiológicos mundiais. Também é um sintoma que tem um custo elevado para os pacientes, familiares, sociedade e para os seviços de saúde em geral, comprometendo a qualidade de vida dos que sofrem com esse problema. As cefaleias primárias, entre elas a enxaqueca e a cefaleia do tipo tensional são classificadas como sendo cefaleias disfuncionais. É importante entender porque esses dois distúrbios não podem ser vistos como dores somáticas, neuropáticas ou viscerais. Neste artigo serão utilizados os termos enxaqueca e migrânea como sinônimos. O objetivo deste estudo foi conceituar dor disfuncional justificar o porquê as cefaleias primárias são consideradas dores disfuncionais.

CONTEÚDO: a) Fisiopatologia da migrânea, a cefaléia primária mais prevalente em consultórios médicos, é explicada como sendo uma doença constituída por crises que podem ter até 5 fases e não ser apenas uma dor de cabeça. As fases da crise da migranea são: sintomas premonitórios, aura, cefaleia, sintomas autonômicos/hipotalamincos e pósdromo. b) Classificar a migranea como dor disfuncional, pois não preenche critérios para classifica-la como dor neuropática ou somática. c) Discutir que tipo de dor são as cefaleias secundárias.

CONCLUSÁO: Pode-se aceitar a ideia de que as cefaleias primárias sejam dores desmodulatórias, mas que as secundárias sejam nociceptivas ou viscerais.

Descritores: Cefaleia, Cefaleias secundárias, Dor disfuncional, Migrânea ou enxaqueca.

1. Faculdade de Medicina de Ribeirão Preto, Departamento de Neurologia, Membro Efetivo da Academia Brasileria de Neurologia, da Sociedade Brasileira para o Estudo da Dor e da Sociedade Brasileira de Cefaleia. Ribeiráo Preto, SP, Brasil.

2. Universidade Estadual do Rio de Janeiro, Clínica de Dor, Rio de Janeiro, RJ, Brasil.

3. Universidade de Sáo Paulo, Faculdade de Medicina, Hospital das Clínicas, Divisão de Neurologia, São Paulo, SP, Brasil.

Conflic of interests: none - Sponsoring sources: none.

Correspondence to:

Rua dos Tucunarés, 735 - Quinta da Alvorada

14110-000 Ribeirăo Preto, SP, Brasil.

E-mail: josespeciali@yahoo.com.br

(c) Sociedade Brasileira para o Estudo da Dor

\section{INTRODUCTION}

Along the last decades, the understanding of mechanisms producing primary headaches has evolved; especially the understanding of migraine pathophysiology. Initially considered primarily a vascular disorder, migraine was then understood as neurovascular disorder ${ }^{1}$. However, the neurovascular model does not supply explanations involving all its aspects, which involve several nervous system levels, because in addition to headache there are also neurovegetative, affective, cognitive and sensory symptoms. Currently, migraine is understood as brain dysfunction, thus primarily a neuronal rather than vascular disorder.

Migraine is a primary, disabling, recurrent or chronic and common headache which may last 24 to $72 \mathrm{~h}$. Pain is in general unilateral, pulsing, with moderate to severe intensity, worsened by daily routine activities, associated to nausea and/or vomiting and/or photophobia and phonophobia. It may or may not be followed by totally reversible symptoms lasting minutes, such as visual and sensory changes or other central nervous system (CNS) symptom (aura). Some patients also have a premonitory phase, preceding in hours or days the onset of headache and including: hyperactivity, hypoactivity, depression, specific appetite for some foods, repeated yawning and other unspecific symptoms (ICHD 3$)^{2}$.

\section{PATHOPHYSIOLOGY REVIEW}

Premonitory symptoms of crises may appear up to $24 \mathrm{~h}$ before pain onset and their nature (sleepiness, fatigue, appetite changes, yawning, etc.) points to hypothalamus as their probable origin. Since migraine brain is extremely sensitive to homeostasis shifts, it is possible that hypothalamic neurons regulating homeostasis and circadian cycles give origin to these premonitory symptoms. Other prodromic symptoms, such as abnormal sensitivity to light, noise and odors, point to brain cortex as the source, and depression and anhedonia to the limbic system ${ }^{3}$

Hypothalamic and brainstem (BS) neurons could start a crisis by two mechanisms: 1 - changing the balance between parasympathetic and sympathetic tone in meningeal vessels, with predominance of parasympathetic tone through upper salivator nucleus (USN), as proposed by Burstein \& Jakubowski ${ }^{4} ; 2$ - decreasing threshold for nociceptive transmission of trigeminal-vascular signals from thalamus to cortex 5 .

Trigeminothalamic neurons are directly influenced by hypothalamic neurons which contain dopamine, histamine, orexin and melanotrophic factor $(\mathrm{MSH})$, and by BS noradrenergic and serotoninergic neurons. Each of these neurotransmitters may change phase activity of thalamic neurons to tonic activity if the influence is excitatory (dopamine and serotonin in high concentrations, norepinephrine, histamine, orexin), or change tonic activity to phased if they are inhibitory (MSH and low concentration of serotonin). These influences on trigeminovascular thalamic neurons provide an anatomic basis to explain some triggering factors which may originate some migraine crises, but not others, and because external stimuli (perfumes) or internal stimuli (sensation of hunger, poor sleep or stress) inconsistently trigger migraine crises, only when interfering and coinciding with the correct circadian phase of BS, hypothalamus and thalamic neurons cyclic rhythm which maintain homeostasis ${ }^{6}$.

It is believed that cortical spreading depression (CSD) is the event underlying migraine aura ${ }^{1,7-9}$. CSD is a complex phenomenon of brain cortex depolarization which has different phases and consists of a wave of strong neural and glial depolarization which slowly propagates $(2-6 \mathrm{~mm} / \mathrm{min})$. Depolarization is triggered by the activation of calcium channels in pyramidal neurons apical dendrites. Once started, CSD is self-propagated in the cortex as a wave traveling through apical dendrites layers and is characterized by ionic homeostasis collapse, deep transmembrane ionic gradient changes and release of neurotransmitters and other intracellular compartment mol- 
ecules $^{10}$. Experimental data support the idea that increased potassium $\left(\mathrm{K}^{+}\right)$ concentration above a critical level is key-element for CSD onset and that the activation of NMDA glutamatergic receptors (NMDAR) is also necessary for its onset or propagation.

It is said that deficient regulation of cortical excitatory-inhibitory balance may, in certain conditions (e.g., in response to migraine triggering factors) lead to cortical circuits hyperactivity, which in turn would increase $\mathrm{K}^{+}$concentration, thus creating conditions for the triggering of $\mathrm{CSD}^{9,10}$.

Neurophysiologic studies show that even in the interictal period, migraine patients are hypersensitive to sensory stimuli and abnormally process sensory information, which is characterized by increased amplitude and decreased habituation of event-related evoked potentials ${ }^{11,12}$ In chronic migraine patients, increased cortical visual excitability follows BS activation and mesencephalic periaqueductal matter (MPM) inhibition, in addition to somatosensory inhibition, which suggests descending inhibitory pathways dysfunction?

Many evidences support the view that migraine is characterized by central dysfunctional pain control. In addition to sensitization of peripheral nociceptors and sensitization of trigeminal caudal nucleus $(\mathrm{TCN})^{13}$, there is central modulation of nociceptive signals which may facilitate or inhibit TCN responses. For example, corticofugal fibers of the insular cortex which project contralaterally may facilitate TCN laminae I-II neurons responses, while primary somatosensory cortical areas generate inhibitory stimuli to laminae III-IV ${ }^{14}$

Several studies document limbic and prosencephalic pathways which influence BS pain modulator circuits, and functional connectivity studies suggest that the anterior cingulated cortex (ACC)-SPA-rostromedial spinal cord complex is a migraine pain modulation network ${ }^{15}$. Altered connectivity of limbic system to BS in migraine patients has been documented, which supports the view of migraine as pain neurolimbic networks disorder and expands the concept of central sensitization, event happening in BS, so as to include a limbic dysfunction. Functional magnetic resonance (MRI) studies in the interictal period have shown dysfunctional interictal dynamics in pain networks of migraine patients, with abnormal connectivity between MPM and limbic system which seems to be progressive, according to longer duration and severity of the disease ${ }^{16}$.

Neurolimbic influences are bidirectional; limbic pathways may modulate or trigger BS process which starts a migraine attack, or the dysfunction of BS structures may change limbic function, influencing mood and coping strategies ${ }^{14}$

Concluding: migraine pathophysiology is complex and would be a recurrent dysfunction of central information processing, which involves major pain processing structures: trigeminovascular system, brainstem and cortex. This susceptibility seems to be partially hereditary and crisis onset may be due to a combination of heterogeneous environmental and internal factors ${ }^{17}$.

\section{Migraine is not neuropathic pain}

Migraine, neuropathic pain (NeuP) and nociceptive pain (NocP) are among most common pains of humanity. Currently, the definition of NeuP proposed by Treede et al. ${ }^{18}$ is been widely used. According to authors, since nociceptive system sensitivity is modulated by its adequate activation (e.g., central sensitization), it is difficult to distinguish "neuropathic dysfunction from physiological neuroplasticity" which occurs in this system as result of a sufficiently strong nociceptive stimulus. So, authors have proposed a change in NeuP definition by removing the word "dysfunction" from the old definition and defining NeuP as "induced by injury or disease affecting the Somatosensory System".

In NocP, pain would be generated by an external noxious stimulus, located outside CNS in a situation where CNS and peripheral nervous system (PNS) would be structurally and functionally intact.

NocP mechanisms stages are then similar to those of NeuP and consist of: peripheral sensitization in nervous terminations and dorsal root ganglion (DRG) causing central sensitization of spinal cord dorsal horn, influenced by ascending brainstem pathways, which would anticipate final pain perception in sensory cortex ${ }^{19}$.

Migraine may be considered visceral pain or NocP. As most solid organs, brain is insensitive to pain. Intracranial structures sensitive to pain are: brain arteries and meningeal walls, venous, venous sinuses and meningeal walls - dura and leptomeninges, which have been defined as brain "cap- sule". In any place of the body, pain comes from nociceptors located in the capsule of solid organs due to inflammation or stretching (described as nociceptive pain); similarly, intracranial pain (where migraine is included) may come from the capsule - meninges - due to inflammation or stretching.

This is the essential similarity between migraine and NocP. Visceral pain is often referred to the corresponding sensitive dermatome as result of coexcitation at dorsal horn level; similarly, migraine is often referred to pericranial and cervical muscles due to coexcitation of trigeminocervical complex - the counterpart in spinal cord dorsal horn. This would be the second similarity of migraine and $\mathrm{NocP}^{19}$.

In migraine, Leão's CSD probably results from changes in membrane patency and ion channels dysfunction, allowing intra and extraneural ion changes of ions $\mathrm{Na}^{+}, \mathrm{K}^{+}, \mathrm{Ca}^{++}$e $\mathrm{Mg}^{++20}$, as already mentioned, which would put it closer to NeuP, in addition to peripheral and central sensitization changes.

So, one could consider that migraine, NeuP and NocP would share a common structural and functional organization consisting of: 1-peripheral sensitization (in DRG or Gasser Ganglion); 2-central sensitization; 3 -modulation at spinal cord, brainstem and thalamus level, before final pain perception in pain cortical matrix (consisting of primary and secondary sensory cortex, prefrontal cortex, anterior cingulum region, insula and amygdala).

So, it could be understood that migraine is not NeuP or NocP. Dysfunctional pain might be the definition of choice, completing the old definition and excluding neuropathic pain - "NS dysfunction".

\section{Migraine: dysfunctional pain}

The concept of dysfunctional pain is relatively new and has gained evidence when the NeuP study group of the International Association for the Study of Pain (IASP) suggested a new neuropathic pain definition in $2008^{18}$ to replace the definition used since $1994^{21}$. By that time, neuropathic pain was defined as pain triggered or caused by primary injury or dysfunction of central or peripheral nervous system.

Bowsher ${ }^{22}$ has published in 1991 one article on neurogenic pain, defining it as pain due to peripheral (PNS) or central (CNS) nervous system dysfunction and lack of nociceptors stimulation by trauma or disease. It had been established the need for the pain process to go through peripheral nociceptors when it was nociceptive, otherwise it would be neurogenic pain.

Neuropathic and neurogenic pain are different from each other by the acceptance of CNS transient perturbation in neurogenic pain, but differences between these two types of pain were forgotten and were not routinely used in pain clinics or publications. Both terms were used as synonyms.

A new concept of neuropathic pain was proposed by a group of neurologists and neurophysiologists ${ }^{18,23}$. They have proposed: "pain directly caused by somatosensory system injury or disease". First, this restricts the triggering event to "injury" or "disease", which could be more objectively documented and moves away from the vague term "dysfunction". Secondly, it restricts the injury to the somatosensory system rather than to "nervous system" as in the previous version. This proposal is closer to what we see in the clinical practice and brings advances in the sense of separating NeuP from other syndromes, having major impact on studies on the subject.

Recently, IASP has accepted this neuropathic pain definition proposal with minor changes in the text: "Pain induced by somatosensory system injury or disease".

Considering this new definition, a large group of painful syndromes would not fit the nociceptive or neuropathic pain groups ${ }^{24}$. As example, fibromyalgia syndrome, mouth-burning syndrome, irritable bowel syndrome, migraine and other primary headaches, complex regional pain syndrome and other diseases having in common the lack of overt tissue injury which would explain the presence of pain ${ }^{25}$. These are considered demodulatory or dysfunctional pains. Dysfunctional painful syndromes encompass a large number of diseases having in common the lack of overt tissue injury to explain the painful syndrome. The term "dysfunctional" remits exactly to the fact that these syndromes are caused by altered nervous system functioning, be it central or peripheral. With the advance of knowledge, our understanding about many diseases classified as dysfunctional syndromes may increase $\mathrm{e}^{24,26}$.

Under the umbrella of dysfunctional pain, many diseases are sheltered, which are very different from each other in terms of symptoms, patho- 
physiology and treatment, which indicates the need for advances in current knowledge, which could give to these so different disorders a common neurological/neurochemical basis. It is believed that neurophisiologic bases of demodulatory pains are located in specific brain regions as it has been shown by sophisticated neuroimaging studies ${ }^{24}$.

\section{Types of pain of primary headaches}

There are more than a hundred causes of headache mentioned in the International Classification of Headache Disorders, $3^{\text {rd }}$ ed. (beta version) ${ }^{2}$. Specific pains of the cephalic segment have not yet been classified according to type of pain. Secondary headaches are possibly nociceptive. In meningitis and related diseases, pain would be generated by stimulation of peripheral nociceptors of large vessels of the base and of meninges by the inflammatory process generating nociceptive pain. The same may be said of expansion injury headaches, in which structures compression, traction or dilatation could stimulate local nociceptors and also generate NocP. The same is true for arteritis and vasculitis in general, when vascular nociceptors would be stimulated ${ }^{2}$.

Type of pain of primary headaches could not be classified as NocP or NeuP. Migraine headache is triggered by stimulation of peripheral nociceptors of trigeminal terminations of meninges inervated by the first trigeminal branch at this level. Would it then be a nociceptive pain? The major difference between this headache and classic nociceptive headache is that in the latter nociceptors stimulation is by their direct aggression by tissue injury and release of local neurotransmitters. In migraine, nociceptors stimulation is by neurogenic inflammation caused by central dysfunction - cortex or specific brainstem nuclei. Neurogenic inflammation is caused by endovascular factors released by local vasodilation, with nociceptors activation.

Meningeal dilatation is primarily caused by CGRG, neurokinins and substance $\mathrm{P}$ retrogradely released by trigeminal terminations. Major difference between classic nociceptive pains and migraine pain is that in the latter peripheral nociceptors stimulation is made by processes started in the NS rather than in the periphery ${ }^{22}$. So, migraine pain has been considered demodulatory pain because processes giving origin to neurogenic meningeal inflammation start in the CNS. They could also not be classified as neuropathic pain due to the absence of specific central or peripheral nervous system injury or disease.

Other primary headaches may be similarly interpreted and are other examples of demodulatory pain.

Central demodulation process in primary headaches is not static, being influenced by several endogenous factors (hormonal, sleep, emotions, phases of life) and exogenous factors (climate, season of the year, food intake, alcoholic drinks, odors, etc.) leading patients to spend days/months/years. asymptomatic, with periods of symptoms exacerbation ${ }^{27}$.
In conclusion, one may accept the idea that primary headaches are demodulatory pains, but that secondary headaches are nociceptive or visceral.

\section{REFERENCES}

1. Goadsby PJ. Pathophysiology of migraine. Neurol Clin. 2009;27:335-60.

2. The International Classification of Headache Disorders, $3^{\text {rd }}$ ed. (beta version). Cephalalgia. 2013;33(9):629-808.

3. Maniyar FH, Sprenger T, Monteith T, Schankin C, Goadsby PJ. Brain activations in the premonitory phase of nitroglycerintriggered migraine attacks. Brain. 2014;137(Pt 1):232-41.

4. Burstein R, Jakubowski M. Unitary hypothesis for multiple triggers of the pain and strain of migraine. J Comp Neurol. 2005;493(1):9-14.

5. . Noseda R, Kainz V, Borsook D, Burstein R. Neurochemical pathways that converge on thalamic trigeminovascular neurons: potential substrate for modulation of migraine by sleep, food intake, stress and anxiety. PLoS One. 2014;9(8):e103929.

6. Pietrobon D, Striessnig J. Neurobiology of migraine. Nat Rev Neurosci. 2003;4(5):386-98

7. Ayata C. Cortical spreading depression triggers migraine attack: pro. Headache. 2010;50(4):725-30

8. Burnstein R, Noseda R, Borsook D. Migraine: multiple processes, complex pathophysiology. J Neurosci. 2015;35(17):6619-29.

9. Vecchia D, Pietrobon D. Migraine: a disorder of brain excitatory-inhibitory balance? Trends Neurosci. $2012 ; 35(8): 507-20$.

10. Pietrobon D, Moskowitz MA. Chaos and commotion in the wake of cortical spreading depression and spreading depolarizations. Nat Rev Neurosci. 2014;15(6):379-93

11. Aurora SK, Wilkinson F. The brain is hyperexcitable in migraine. Cephalalgia. 2007;27(12):1442-53.

12. Coppola G, Pierelli F, Schoenen J. Is the cerebral cortex hyperexcitable or hyperresponsive in migraine? Cephalalgia. 2007;27(12):1427-39

13. Burstein R, Jakubowski M, Rauch SD. The science of migraine. J Vestib Res. 2011;21(6):305-14.

14. Maizels M, Aurora S, Heinricher M. Beyond neurovascular: migraine as a dysfunctional neurolimbic pain network. Headache. 2012;52(10):1553-65.

15. Kong J, Tu PC, Zyloney C, Su TP. Intrinsic functional connectivity of the periaqueductal gray, a resting fMRI study. Behav Brain Res. 2010;211(2):215-9.

16. Mainero C, Boshyan J, Hadjikhani N. Altered functional magnetic resonance imaging resting-state connectivity in periaqueductal gray networks in migraine. Ann Neurol. 2011;70(5):838-45.

17. Gantenbein A, Sándor P, Sándor P, Riederer F, Schoenen J. A comprehensive view of migraine pathophysiology. In: Fernández-de-las-Peñas C, Chaitow L, Schoenen J, (editors). Multidisciplinary management of migraine: pharmacological, manual, and others therapies, USA: Jones\&Bartlett Learning; 2013. 67-79p.

18. Treede RD, Jensen TS, Campbell JN, Cruccu G, Dostrovsky JO, Griffin JW, et al. Neuropathic pain redefinition and a grading system for clinical and research purposes. Neurology. 2008;70(18):1630-5. 9. Chakravarty A, Sen A. Migraine, neuropathic pain and nociceptive pain: towards a unifying concept Med Hypotheses. 2010;74(2):225-31.

20. Lauritzen M, Kraig RP. Spreading depression. In: Olesen J, Goadsby PJ, Ramadan NM, Tfelt-Hansen P, Welch KMA, (editors). The headaches. Philadelphia: Lippincott, Williams \& Wilkins; 2006. 269-74p.

21. Merskey H, Bogduk N, (editors). Taskforce on taxonomy of the International Association for the Study of Pain (IASP): classification of chronic pain. Description of pain syndromes and definitions of pain terms. $2^{\text {nd }}$ ed. Seattle: IASP Press; 1994. 209-14p.

22. Bowsher D. Neurogenic pain syndromes and their management. Br Med Bull. 1991;47(3):644-66

23. Jensen TS, Baron R, Haanpää M, Kalso E, Loeser JD, Rice ASC, et al. A new definition of neuropathic pain. Pain. 2011;14(1):1-2.

24. Andrade DC, Speciali JG. Conceito de dor neuropática. In: Dor neuropática avaliaçăo e tratamento, $1^{a}$ ed. São Paulo: Leitura Médica; 2012. 11-6p.

25. Eisenberg E, Chistyakov AV, Yudashkin M, Kaplan B, Hafner H, Feinsod M. Evidence for cortical hyperexcitability of the affected limb representation area in CRPS: a psychophysical and transcranial magnetic stimulation study. Pain. 2004;113(1-2):99-105.

26. Wood PB, Glabus MF, Simpson R, Patterson JC 2nd. Changes in gray matter density in fibromyalgia: correlation with dopamine metabolism. J Pain. 2009;10(6):609-18.

27. Speciali JG. Entendendo a Enxaqueca. Ribeirăo Preto: Funpec Editora; 2003. 